\title{
Channel Assessment Tools for Rapid Watershed Assessment
}

US Army Corps

of Engineers ${ }_{\circledast}$

by Chris Haring and David Biedenharn

PURPOSE: Existing Delta Headwaters Project (DHP) watershed stabilization studies are focused on restoration and stabilization of degraded stream systems. The original watershed studies formerly under the Demonstration Erosion Control (DEC) Project started in the mid-1980s. The watershed stabilization activities are continuing, and because of the vast number of degraded watersheds and limited amount of yearly funding, there is a need for developing a rapid watershed assessment approach to determine which watersheds to prioritize for further work.

The goal of this project is to test the FluvialGeomorph (FG) toolkit to determine if the Rapid Geomorphic Assessment approach can identify channel stability trends in Campbell Creek and its main tributary. The FG toolkit (Haring et al. 2019; Haring et al. 2020) is a new rapid watershed assessment approach using high-resolution terrain data (Light Detection and Ranging [LiDAR]) to support U.S. Army Corps of Engineers (USACE) watershed planning. One of the principal goals of the USACE SMART (Specific Measureable Attainable Risk-Informed Timely) Planning is to leverage existing data and resources to complete studies. The FG approach uses existing LiDAR to rapidly assess either reach-specific analysis for smaller more focused studies or larger watersheds or ecosystems. The rapid assessment capability can reduce the time and cost of planning by using existing information to complete a preliminary watershed assessment and provide rapid results regarding where to focus more detailed study efforts.

BACKGROUND: The DHP seeks to develop and demonstrate a watershed systems approach to address problems associated with watershed instability: erosion, sedimentation, flooding, and environmental degradation. Initiated by the federal government in 1984, DHP activities targeted 16 watersheds comprising 2,626 $\mathrm{mi}^{2 *}$ within the Yazoo River Basin in the Lower Mississippi Valley. Primary features that are being utilized to achieve the project goals include grade control structures, floodwater retarding structures, bank-stabilization measures, pipe drop structures, and land-treatment measures. A key component of the DHP is monitoring the system to determine the impact of various features with respect to reductions in sediment delivery. Monitoring also provides for the development of advanced technologies that can be transferred to projects outside of the DHP watersheds.

Integrating and further increasing the USACE knowledge base of DHP watershed and regional sediment management approaches is vital to the successful implementation of the SMART Planning paradigm. Watershed management, in this context, includes the evaluation of sediment sources, pathways, and sinks, and the impacts of various sediment management features on

\footnotetext{
${ }^{*}$ For a full list of the spelled-out forms of the units of measure used in this document, please refer to US Government Publishing Office Style Manual, 31st ed. (Washington, DC: US Government Publishing Office 2016), 248-52, https:/www.govinfo.gov/content/pkg/GPO-STYLEMANUAL-2016/pdf/GPOSTYLEMANUAL-2016.pdf.
} 
channel stability throughout a watershed. Watershed management also includes the design of equilibrium channels and siting for grade control and bank-stabilization measures. By utilizing findings from geomorphic assessments, in conjunction with selective surveying to obtain general slope and cross-sectional data, watershed plans for flood control, channel stabilization, regional sediment management, and habitat enhancement can be developed more rapidly than existing approaches. Establishing and applying this rapid assessment framework in a DHP watershed through this research and development effort will assist all USACE Districts by providing improved guidance for rapid watershed assessment for river engineering activities while adhering to the SMART Planning Principles.

FLUVIALGEOMORPH (FG) APPROACH: The FG-Rapid Geomorphic Assessment (RGA) approach outlined in Haring and Doughtery ${ }^{*}$ is divided into three primary workflows. The first workflow, which is the subject of this paper, defines Level 1-Channel Stability Analysis (CSA) for stream channel reaches within the study watershed (Figure 1). The Level 1 CSA evaluates both LiDAR-based longitudinal water surface profiles and channel cross-sections. This provides a reconnaissance level method to identify potential areas of concern based on LiDAR water surface or dry channel slope profiles and cross-sectional area comparative analysis. The CSA provides a basis for identifying potential areas of interest where channel degradation, aggradation, or widespread channel changes are observed. This approach is used to qualitatively identify sediment sources, pathways, and sinks based on channel stability analysis within the reach or larger stream network.

If necessary, the second and third levels of the FG-RGA can be used to provide further refinement via Channel Dimensional Analysis and Planform Dimension Analysis, respectively. The final product of the Level 2 and 3 analysis is a reach level report that maps details of the channel and planform metrics. These metrics are a diagnostic rating based on standardized or user-defined geomorphic thresholds. The metrics are then mapped by color-coded signals providing a comprehensive geomorphic assessment at the reach or watershed scale based on empirically derived geomorphic metrics. The FG-RGA Levels 1, 2, and 3 are defined in more detail in the unpublished Haring and Dougherty technical note.

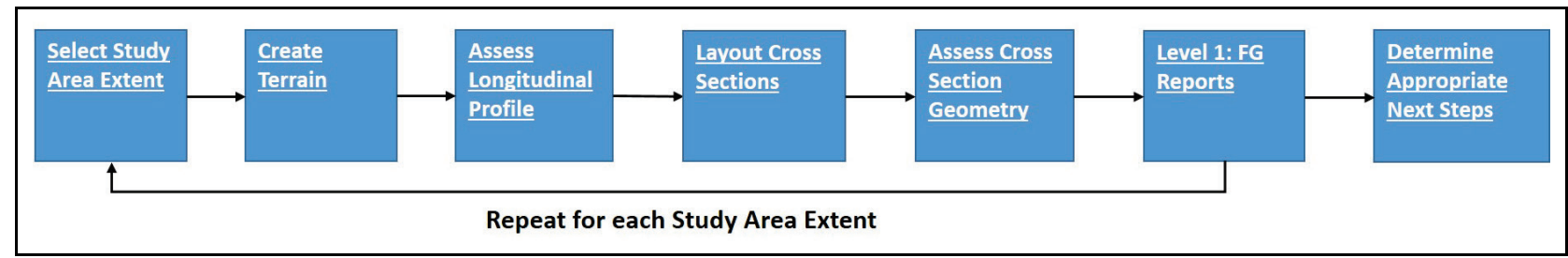

Figure 1. FluvialGeomorph (FG)-Level 1: CSA.

CAMPBELL CREEK CONSTRUCTION HISTORY: Campbell Creek is a small stream in the Batupan Bogue Watershed, which flows into the Yalobusha River just downstream of the Grenada Reservoir (Figure 2). The Campbell Creek watershed is $3.9 \mathrm{mi}^{2}$ with the majority in Grenada County and the downstream section in northeast Montgomery County. Historically,

\footnotetext{
${ }^{*}$ Haring, C. H., and M. P. Dougherty. In preparation. Geomorphic Metrics Used in FluvialGeomorph. ERDC/CHL Coastal and Hydraulics Engineering Technical Note. Vicksburg, MS: U.S. Army Engineer Research and Development Center.
} 
Campbell Creek has experienced channel degradation and widening, primarily as a result of channelization activities in the watershed. In response to this instability, the USACE conducted detailed geomorphic and engineering studies in the mid-1980s aimed at developing stabilization plans for the stream system. As part of these studies, a detailed channel survey was conducted in 1986, which recorded thalweg elevations on a $50 \mathrm{ft}$ interval (Figure 3). Note that the 1986 survey team surveyed the wrong channel downstream at approximately Station 3700. Therefore, this portion of the thalweg survey is invalid. Based on these studies, a stabilization plan was developed for Campbell Creek that included three low drop grade control structures. The proposed location and elevation of these three structures are shown in Figure 4. Further refinements were made to the stabilization plan, and in 1991 another thalweg survey was acquired. A comparison of the 1986 and 1991 surveys (Figure 4) shows that there was significant channel degradation during this time period, with some areas experiencing over $10 \mathrm{ft}$ of channel incision. As a result of these channel changes, the location and elevation of the proposed grade control structures had to be revised. These three structures were constructed in the early 1990s, and the as-built locations and elevations are shown in Figure 4. Recent DHP monitoring of Campbell Creek indicates that portions of the channel were still experiencing channel degradation and bank instabilities, and it was selected as a Regional Sediment Management (RSM) case study to apply the recently developed FG-Level 1 CSA approach.

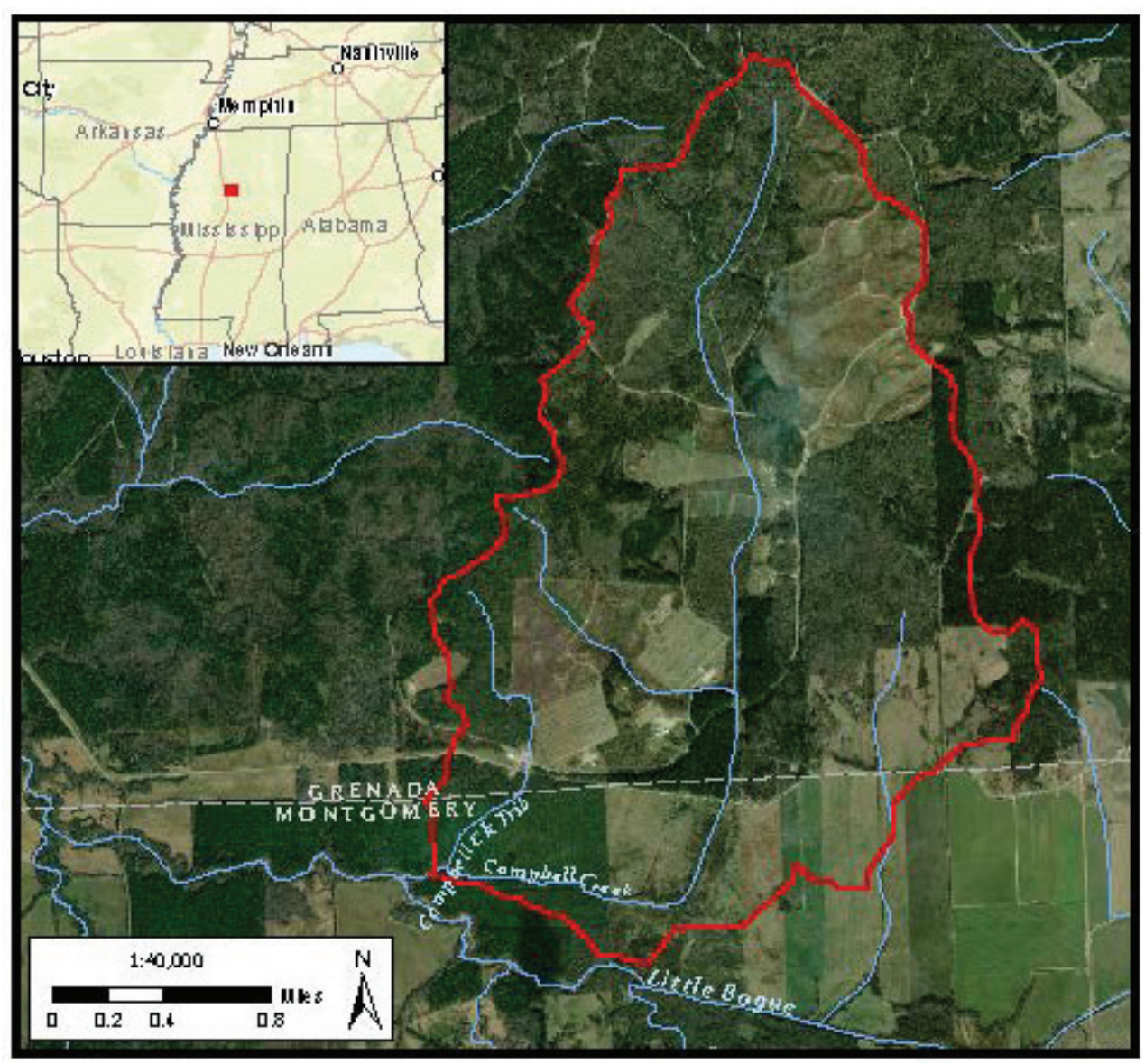

Figure 2. Campbell Creek watershed analysis reaches. 


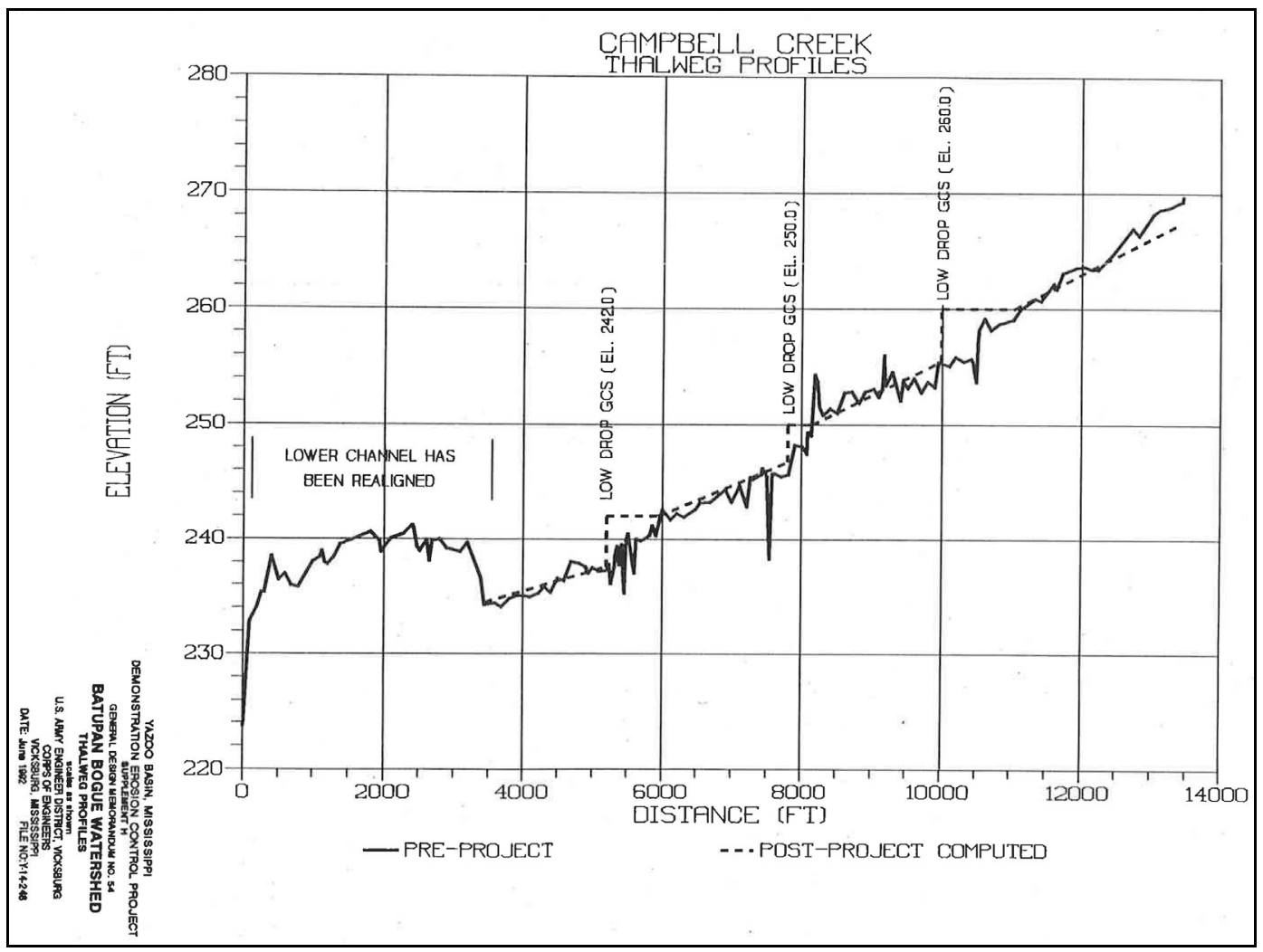

Figure 3. Campbell Creek 1986 channel survey.

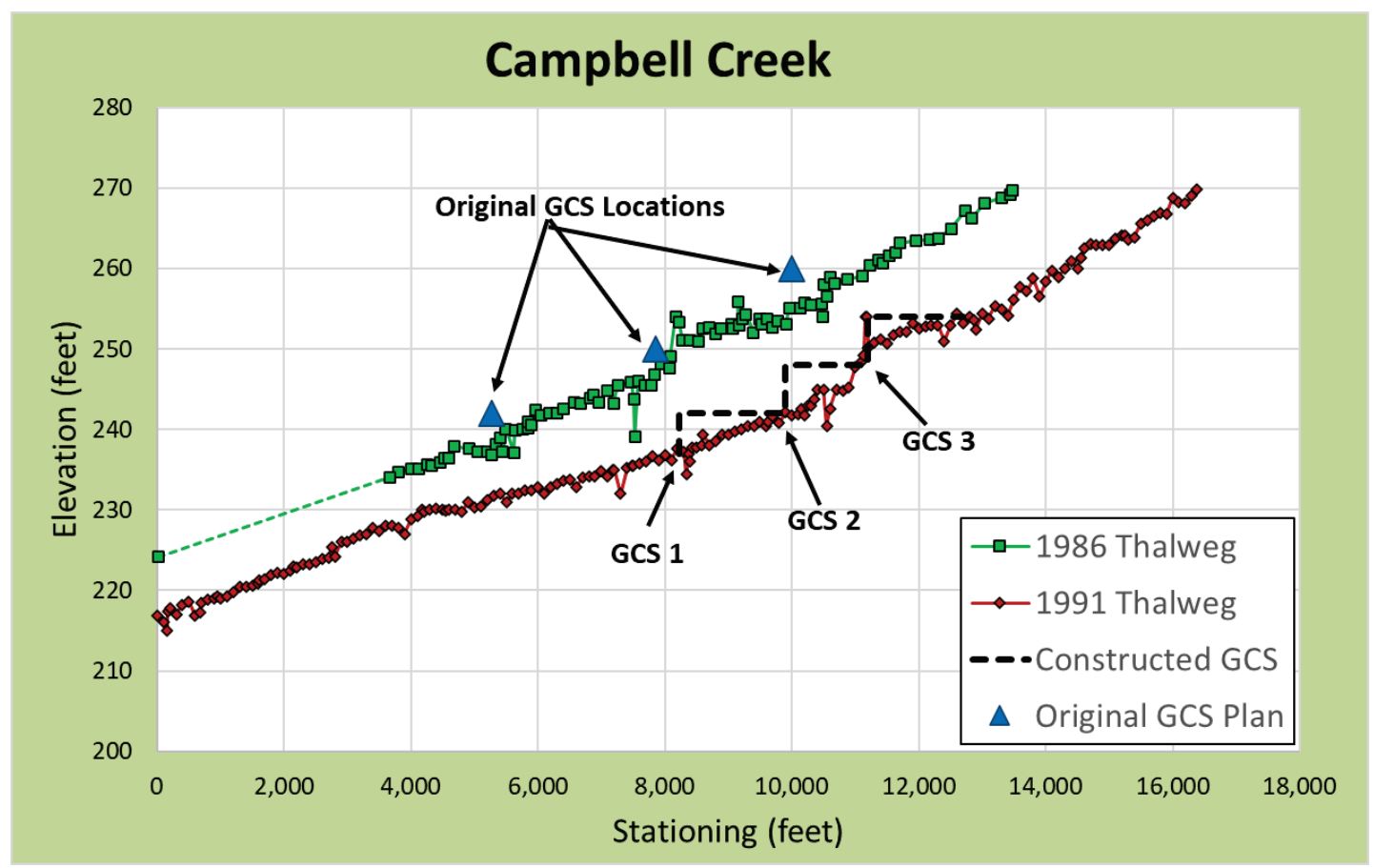

Figure 4. 1986 and 1991 thalweg surveys on Campbell Creek. Note: because of the survey bust in the 1986 survey, the downstream segment was drawn as a straight (dashed) line between approximately Station 3700 and the confluence with Little Bogue, where the elevation was known to be correct. 
RSM APPROACH: The Campbell Creek study was divided into four components: (1) field investigations, (2) acquisition and development of LiDAR data, (3) data analysis, and (4) stabilization recommendations.

Field Investigation. The first step was a field investigation of the channel system in October 2019. Figure 5 shows the limits of this field investigation along with pertinent geomorphic features. An ArcGIS Collector app was used via cell phone to take pictures and provide locations along the stream channel transect survey (Figure 5).

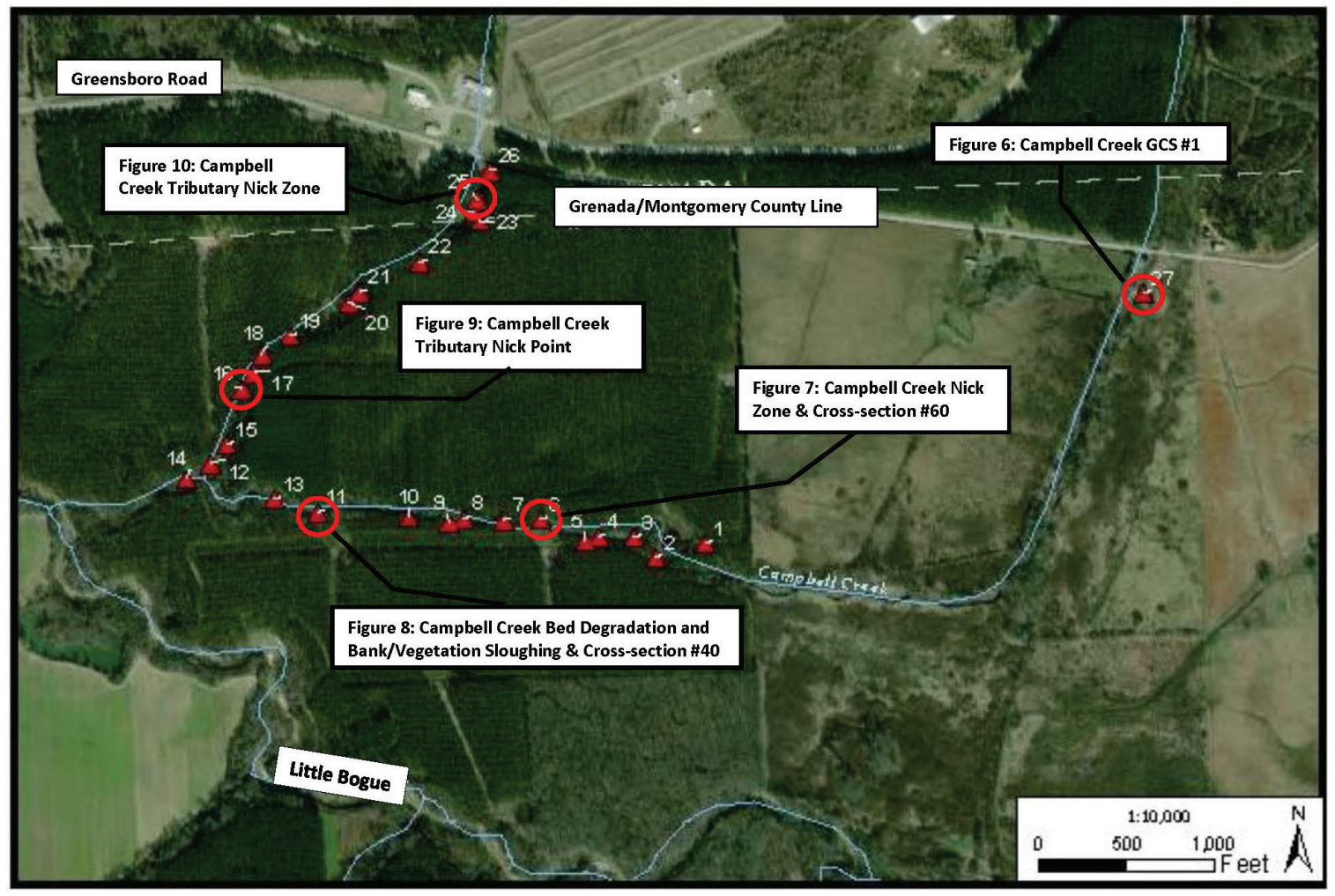

Figure 5. Campbell Creek field investigation with ArcGIS collector point locations.

Photographs of typical channel conditions along Campbell Creek and Campbell Creek Tributary are shown in Figures 6 through 10. These investigations reveal that the channel downstream of the lowermost grade control structure (GCS No. 1; Figure 5) is in a degradational regime, as is most of the entire reach of the Campbell Creek Tributary. In most locations, the bed of the stream had incised into a hard clay material (Figure 10). Although this material is relatively resistant to erosion, there was obvious evidence that the bed was still actively degrading, albeit at a slow rate. 


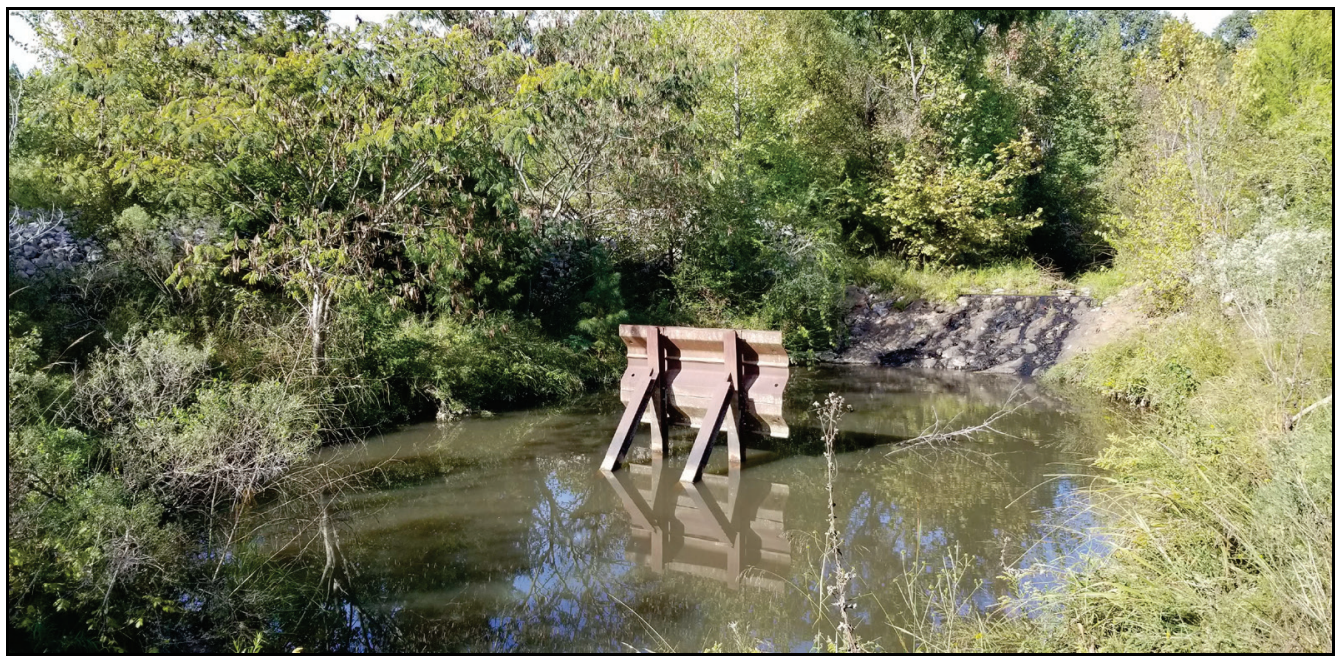

Figure 6. Campbell Creek grade control structure \#1.

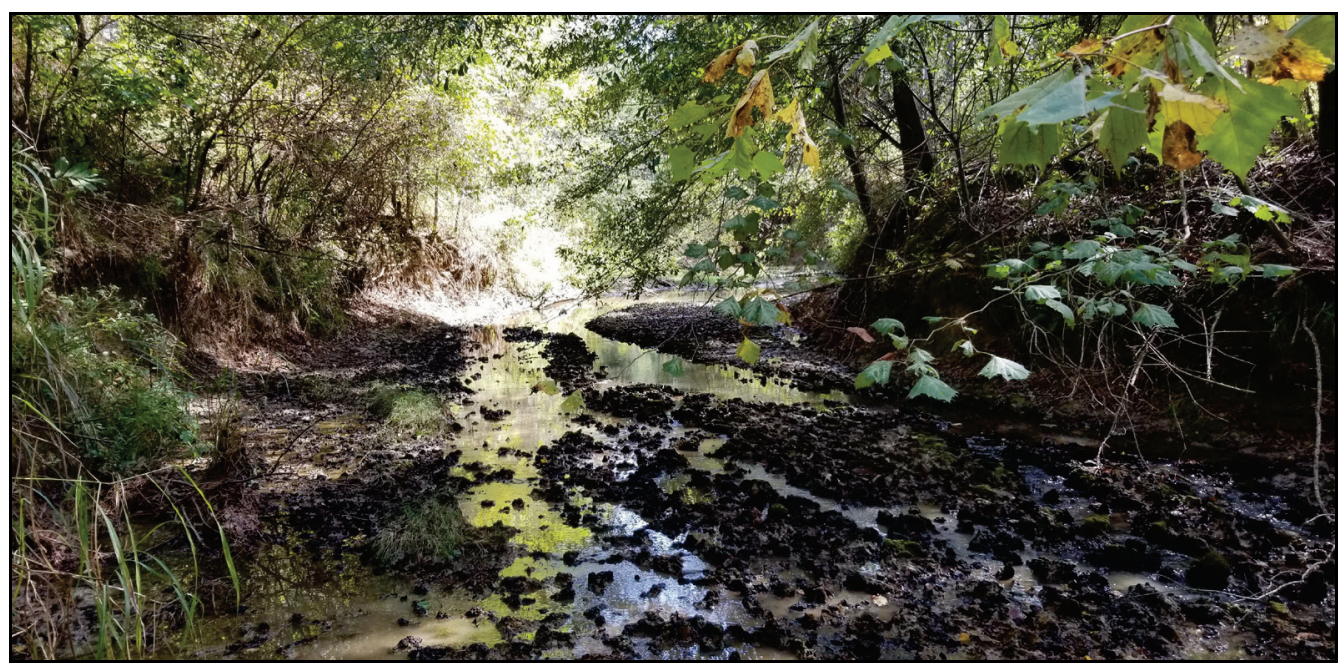

Figure 7. Campbell Creek field identified nick zone in semi-resistant clay bed.

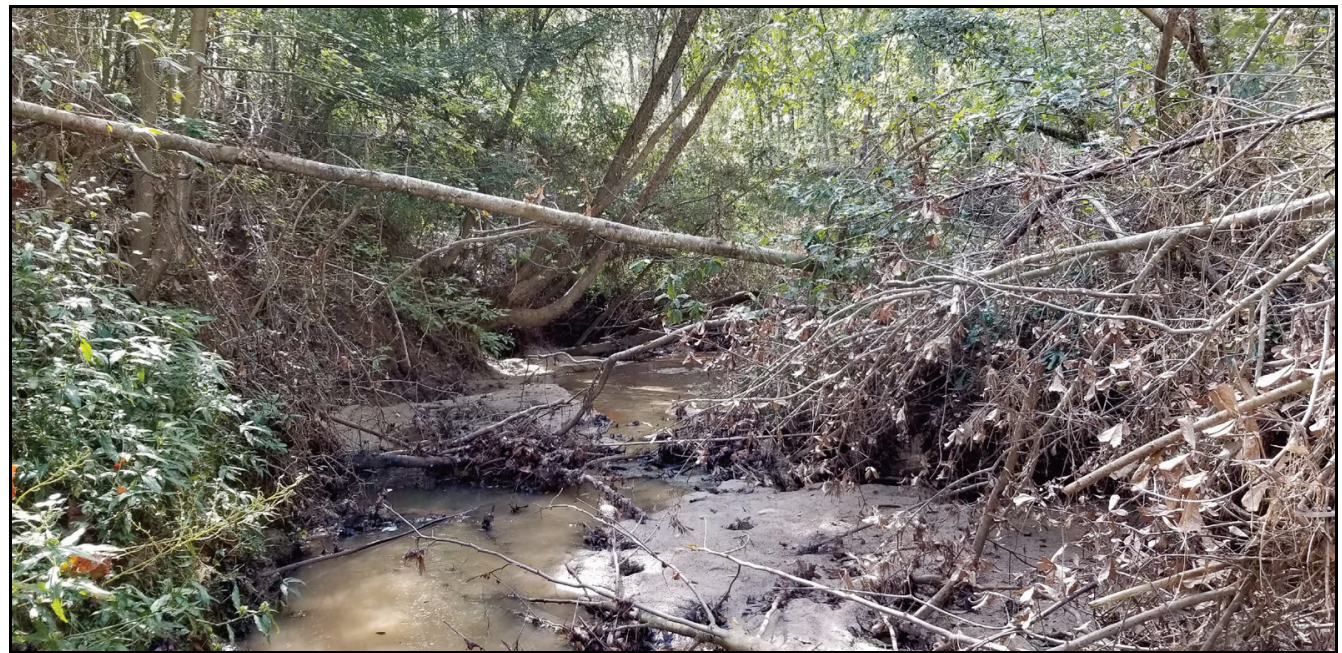

Figure 8. Campbell Creek field identified bed degradation with sloughing bank and vegetation. 


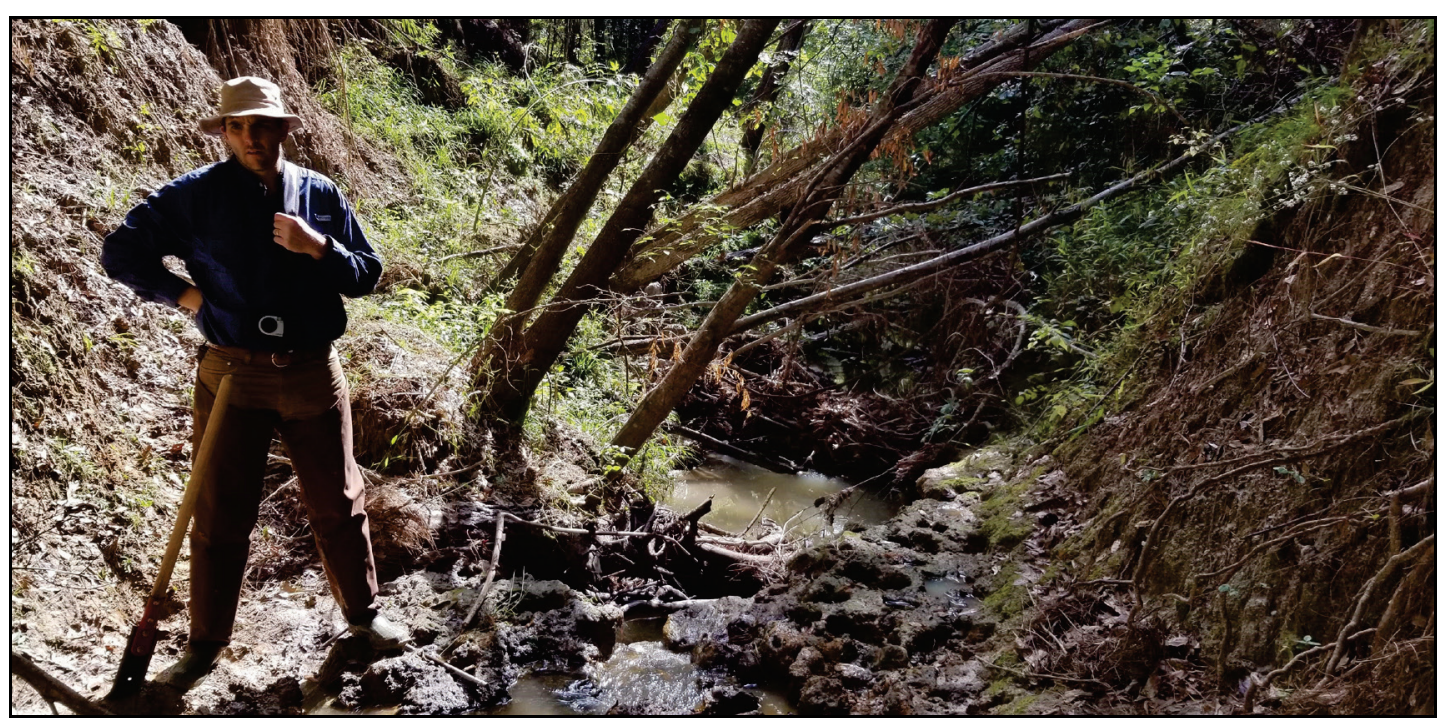

Figure 9. Campbell Creek Tributary nick point with channel widening and sloughing bank and vegetation immediately downstream.

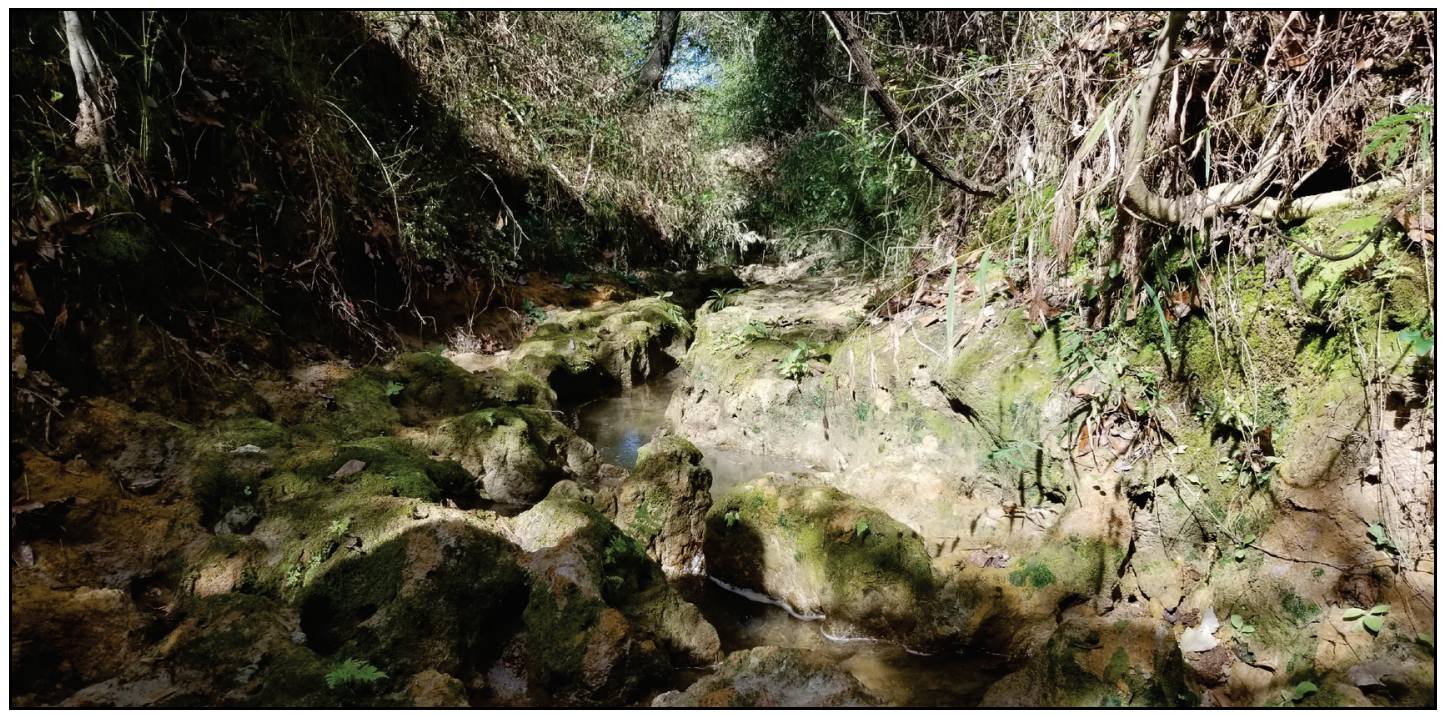

Figure 10. Campbell Creek Tributary nick zone downstream of James H. Biddy Road culverts.

Acquisition and Development of LiDAR Data. The next step in the process was the acquisition of LiDAR survey data to assist in the geomorphic assessment. The Grenada County, Mississippi, LiDAR data were downloaded from the MARIS (Mississippi Automated Resource Information System) site:

\section{https://www.maris.state.ms.us/HTM/DownloadData/LIDAR.html}

Based on the Mississippi LiDAR collection map, the COE Delta Phase II - 2010 data cover Grenada County. The LASer (LAS) was downloaded by flightline but was unprocessed. Each point was not classified. The ArcPro automated classification ground tool was used, taking approximately 4 days to classify the ground points from the flightlines. An LAS Dataset was created and then a $1 \mathrm{ft}$ digital elevation model (DEM). The flightlines from Grenada County crossed into Montgomery County allowing a visual comparison of the two DEMs, which were 
visually similar. MXDs (Map Exchange Documents) for Campbell Creek are available at the following link:

\section{|lmvrdfs $\mid$ egis $\mid$ Work $\mid$ Office $\mid$ Regional $|E R D C| E M R R P$ Sediment $\mid$ CampbellsCreek}

The 2014 LiDAR data for Montgomery County, Mississippi, was discovered on the U.S. Geological Survey (USGS) Rocky FTP site:

ftp://rockyftp.cr.usgs.gov/vdelivery/Datasets/Staged/NED/LPC/projects/USGS_LPC_MS_Laurel 2014 LAS 2015/.

The LAS tiles were downloaded, and a LAS dataset was created. The dataset was filtered for ground, water, and rail; then, a $1 \mathrm{ft}$ DEM was created.

Data Analysis. For comparison purposes, the 2014 LiDAR data were initially analyzed using the RGA-Level 2 protocols which located cross sections based on DEM-identified narrow-riffle locations. This profile is shown in Figure 11. This profile appeared to provide a reasonable representation of the overall channel profile. However, several key features such as grade control structures, culverts, and other major breaks in grade were not captured. The RGA-Level 2 approach is focused on the development of hydraulic geometry parameters, and therefore crosssection locations are selected at identified riffle locations, which may be spaced too far apart to capture many of the local breaks in the channel grade. For this reason, the LiDAR data were reanalyzed using the RGA-Level 1 approach, selecting cross sections every $50 \mathrm{ft}$. As shown in Figure 11, this survey using the $50 \mathrm{ft}$ spacing captured the three grade control structures as well as other significant breaks in grade. Similar profiles were developed for Campbell Creek Tributary (Figure 12). As shown in Figure 12, the profile developed using the $50 \mathrm{ft}$ (RGA-Level 1) cross-section spacing provided a much more detailed view of the channel grade than the RGA-Level 2 approach.

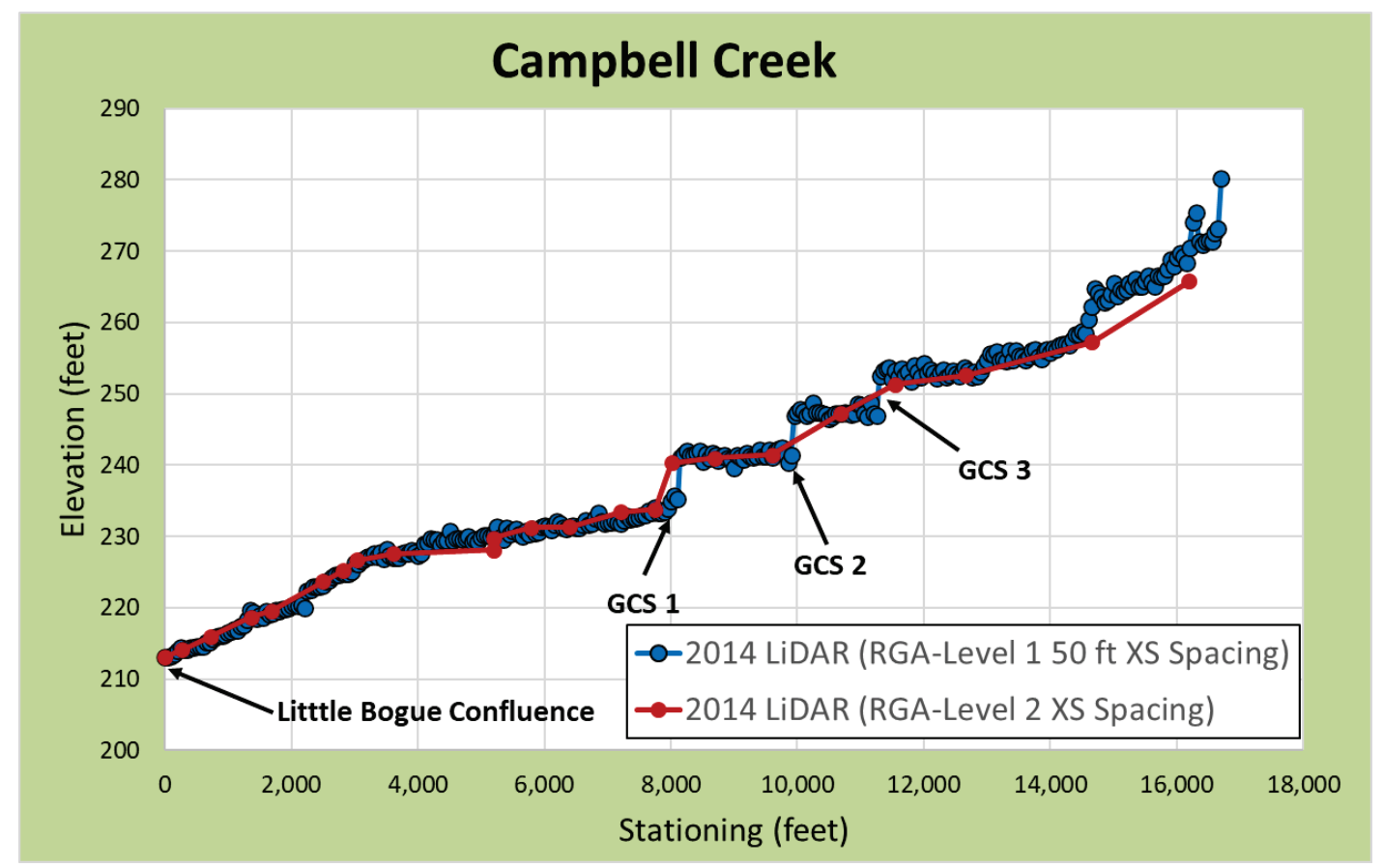

Figure 11. Campbell Creek 2014 LiDAR-RGA Level 1 and 2 profile plot comparison. 


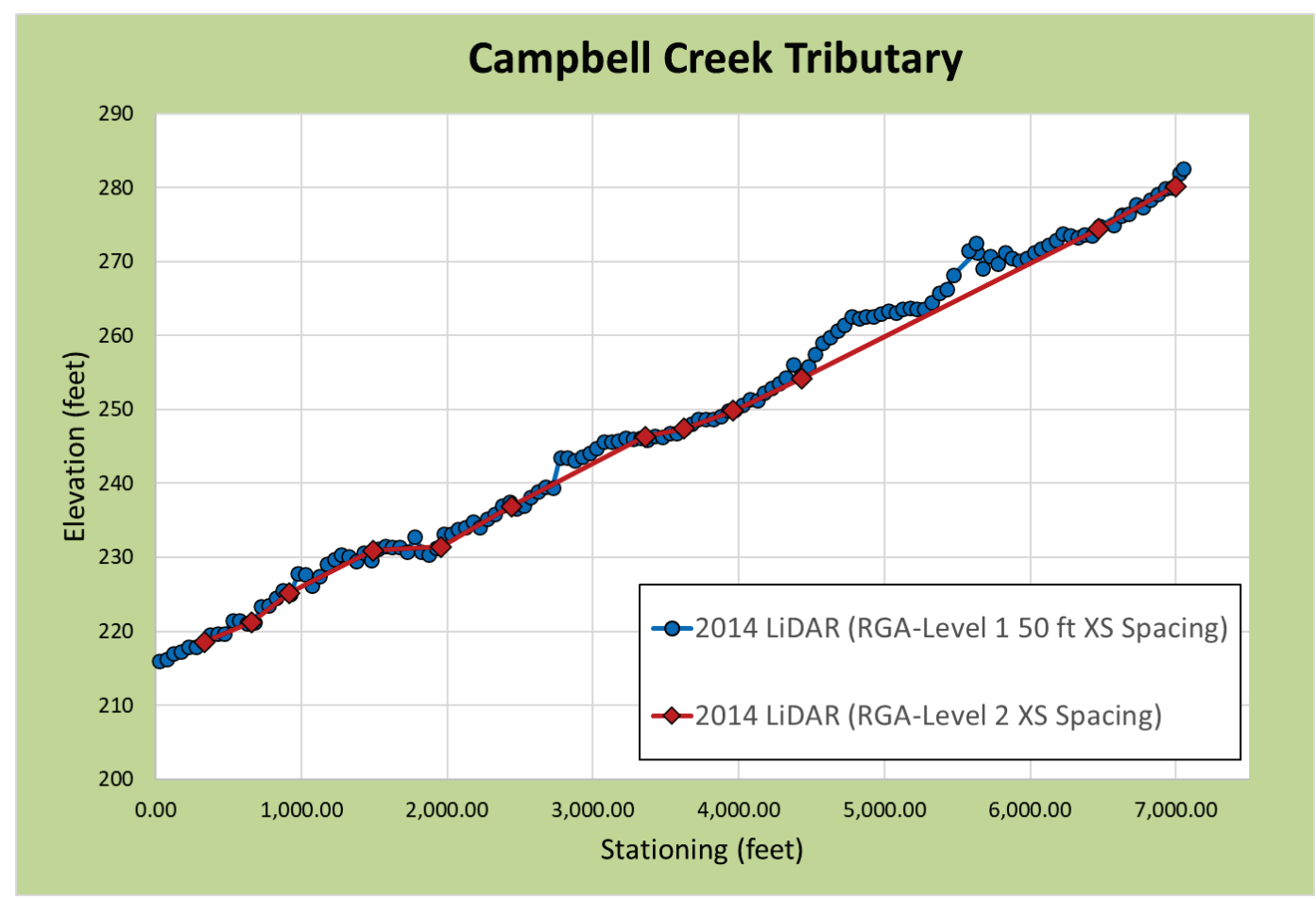

Figure 12. Campbell Creek Tributary 2014 LiDAR-RGA Level 1 and 2 profile plot comparison.

As second part of the FG Level-1 CSA analysis, cross-section comparisons from Figures 7 and 8 are analyzed to identify potential channel degradational and aggredational trends within the reach or watershed. During the field site visit, visual field observations were easy to make based on the presence of resistant bed materials and assessing channel dimensions. As an example, Figures 13 and 14 (locations in Figure 5; photos in Figures 7 and 8) illustrate stream channel changes to cross-sectional dimensions and terrace elevation connections. The data in each figure provides the channel dimension comparisons for each cross section. Between the two sites there is an insignificant increase in the watershed size of $0.08 \mathrm{mi}^{2}$ and increase of $10 \mathrm{cfs}$ (USGS StreamStats 2-year discharge increase from 1260 to $1270 \mathrm{cfs}$ ), but large increases in all hydraulic channel characteristics such as channel depth, cross-sectional area, and others illustrated in the crosssectional summary tables. Mapping the cross-sectional area increases and decreases provide locations for identifying potential channel instability and localized nick points or zones. Those locations can then be assessed using detailed survey methods. Geomorphic comparisons of the terrace levels and hydraulic geometry relationships provide further understanding into channel evolution within the watershed. Additional analysis can be completed to compare specific reach relationships such as stream power, shear stress, entrenchement ratios, and other geomorphic indicators in RGA Level 2 and 3. 


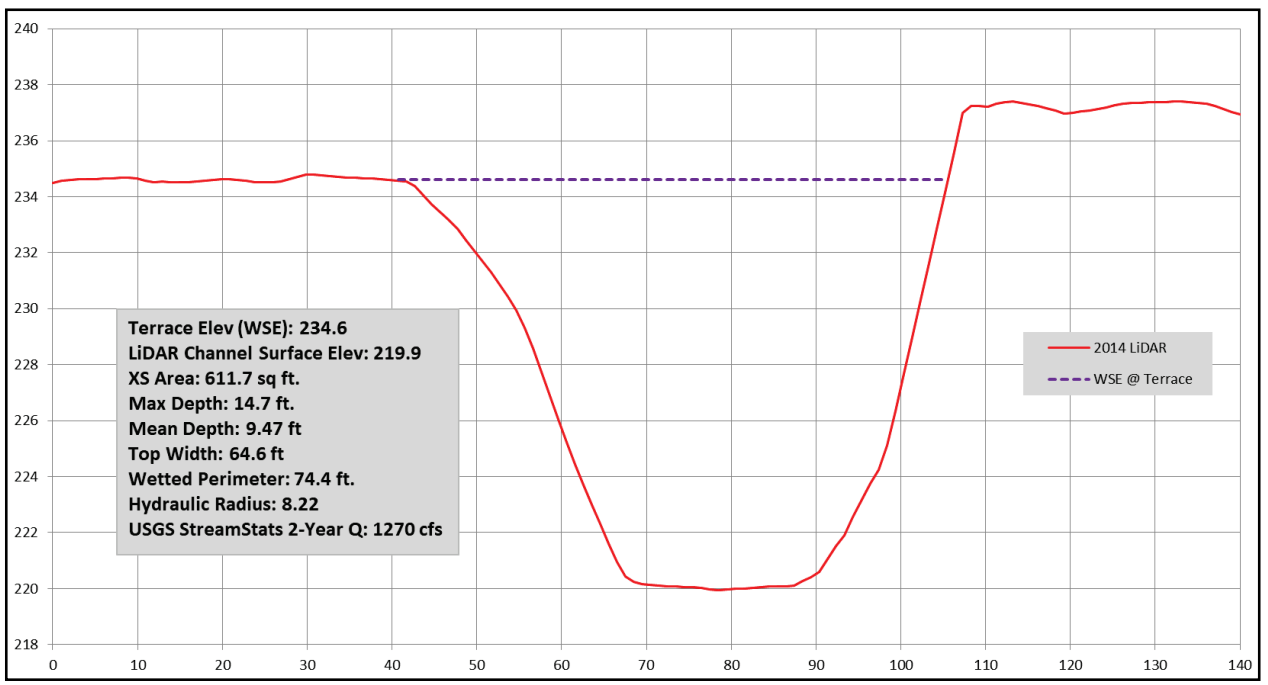

Figure 13. Campbell Creek cross section \#40 associated with Figure 8.

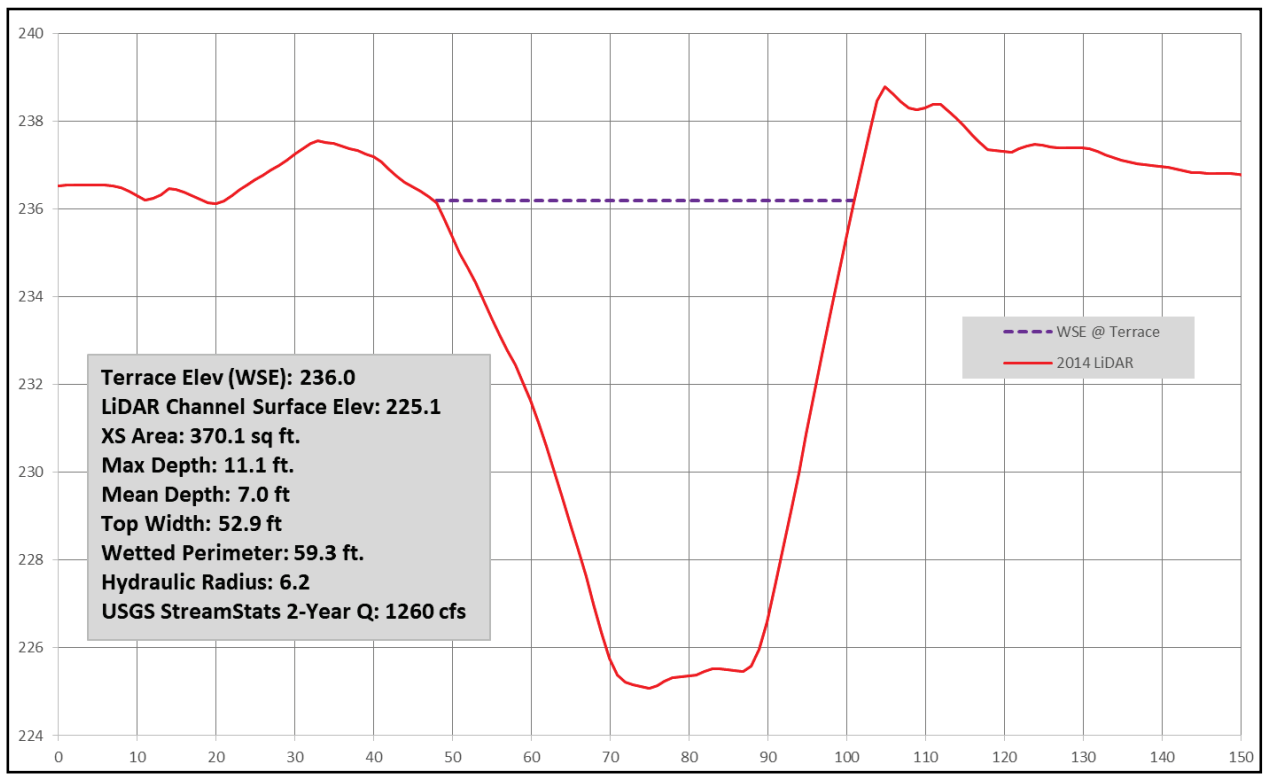

Figure 14. Campbell Creek crosssection \#60 immediately upstream of Figure 7.

One criticism of using LiDAR to represent bed profiles is the limitation with respect to penetrating the water surface. Consequently, the elevations shown may be the water surface rather than the true bed of the channel. While this is a real issue that must be considered, it is often not a significant problem in many small streams where the water depths at base flow conditions may be only a few inches to a foot. Obviously, this depends on the stream and the flow at the time the LiDAR was flown, but for Campbell Creek the LiDAR-depicted elevations were believed to be within half a foot or less of the actual channel bed. Obvious exceptions occur upstream of the grade control structures or at other localized areas where ponded water existed.

Through the DHP monitoring program, empirical relationships between channel slope and drainage area were developed. These curves were developed by calculating the channel slope and drainage for stream reaches that were identified as being in a Channel Evolution Model (CEM) 
Type IV or V (Schumm et al. 1984). CEM Type IV and V reaches represent reaches that have attained or are approaching dynamic equilibrium. The slope-drainage area relationship for CEM Type IV and V reaches is shown in Figure 15. The Campbell Creek study area, with a drainage area of approximately $3.9 \mathrm{mi}^{2}$, has an equilibrium slope of approximately 0.0019 .

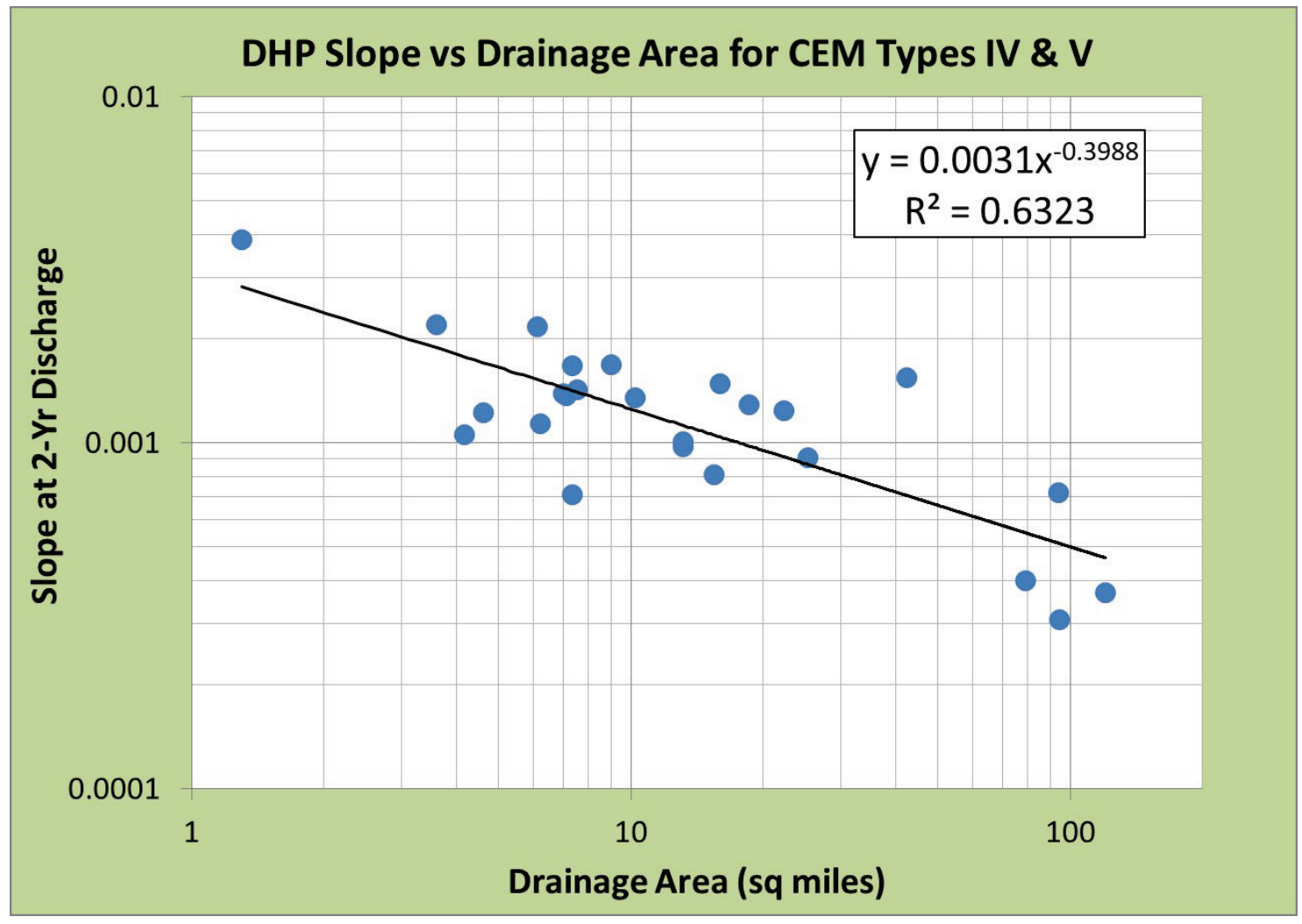

Figure 15. Channel slope vs. drainage area for CEM Types IV and V reaches within the DHP watersheds.

The channel slope based on the 2014 LiDAR was determined for three reaches along Campbell Creek (Figure 16). As shown, the lower and upper reaches have bed slopes that are considerably greater than the equilibrium slope of 0.0019 . These two reaches are expected to be degradational based on this comparison. The middle reach, which extends downstream from GCS 1 to approximately Station 4000 , had a slope of only approximately 0.0012 , which was slightly less than the equilibrium slope. This reach is expected to be in equilibrium or slightly aggradational based on the empirical analysis. 


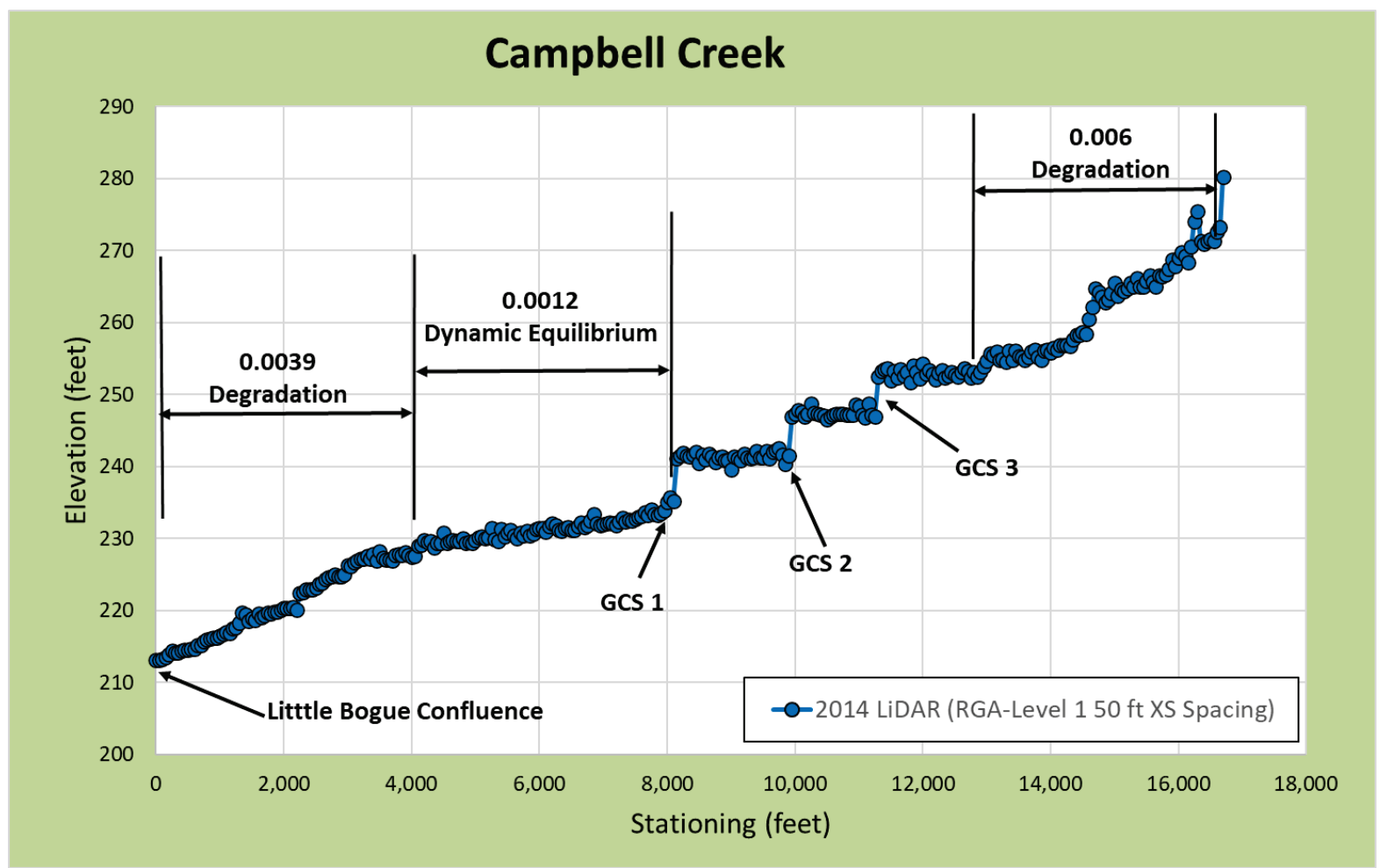

Figure 16. Channel Slope for reaches of Campbell Creek equilibrium slope is approximately 0.0019 .

Note that these stability assessments are based solely on the empirical relationships. Therefore, these assessments must be field verified before making a final judgement about the stability of the reaches. As mentioned previously, the field investigations indicate that the channel downstream of GCS 1 was primarily in a degradational regime. Therefore, there is considerable uncertainty about the middle reach being in an equilibrium or slightly aggradational regime, and the general consensus is that this reach is likely to be degradational.

The Campbell Creek Tributary only has a drainage area of approximately $0.4 \mathrm{mi}^{2}$, and the equilibrium slope is approximately 0.0047 . However, because this drainage area is beyond the lower limits of the data in Figure 15, there is considerable uncertainty with this slope estimate. This tributary is extremely steep with an overall slope of approximately 0.0091 , which is twice the calculated equilibrium slope. This slope comparison coupled with the field indicators suggests that the Campbell Creek Tributary is in a degradational regime.

Stabilization Recommendations. A primary goal of this RSM effort is to demonstrate how the FG RGA-Level 1 approach can be used in a planning study to layout stabilization features along a stream. Using the 2014 LiDAR survey coupled with a preliminary field and geomorphic assessment, a series of grade control structures were developed for Campbell Creek. Although the 2014 survey is 6 years old and therefore does not represent the present-day condition, it will be used herein to demonstrate the design approach. In an actual study, an existing condition survey should be obtained.

To aid in the development of a grade control plan, Campbell Creek was divided into four reaches as shown in Figure 17. For this effort, all structures are sloping rock riffle type of grade control structures that have drop heights ranging from 3 to $4 \mathrm{ft}$ (Newbury and Gaboury 1993). Reach 1 is 
the downstream-most reach, and as discussed previously, was identified as a severely degradational reach. For this reach, four grade control structures are planned (Figure 17). The next upstream reach is Reach 2. The channel slopes in Reach 2 are much less than in Reach 1, but according to the geomorphic assessment, this reach was still considered to be degradational, and therefore grade control are needed. As shown in Figure 17, two grade control structures would be required for this reach. Reach 3 is the reach that is currently stabilized with three existing low drop grade control structures, and analysis of the profile data indicates that no additional grade control is needed in this reach. The most upstream reach is Reach 4, which is a severely degrading. Five grade control structures are planned for this reach. Because of the extremely steep slopes in this reach, several of the structures are spaced very close to each other.

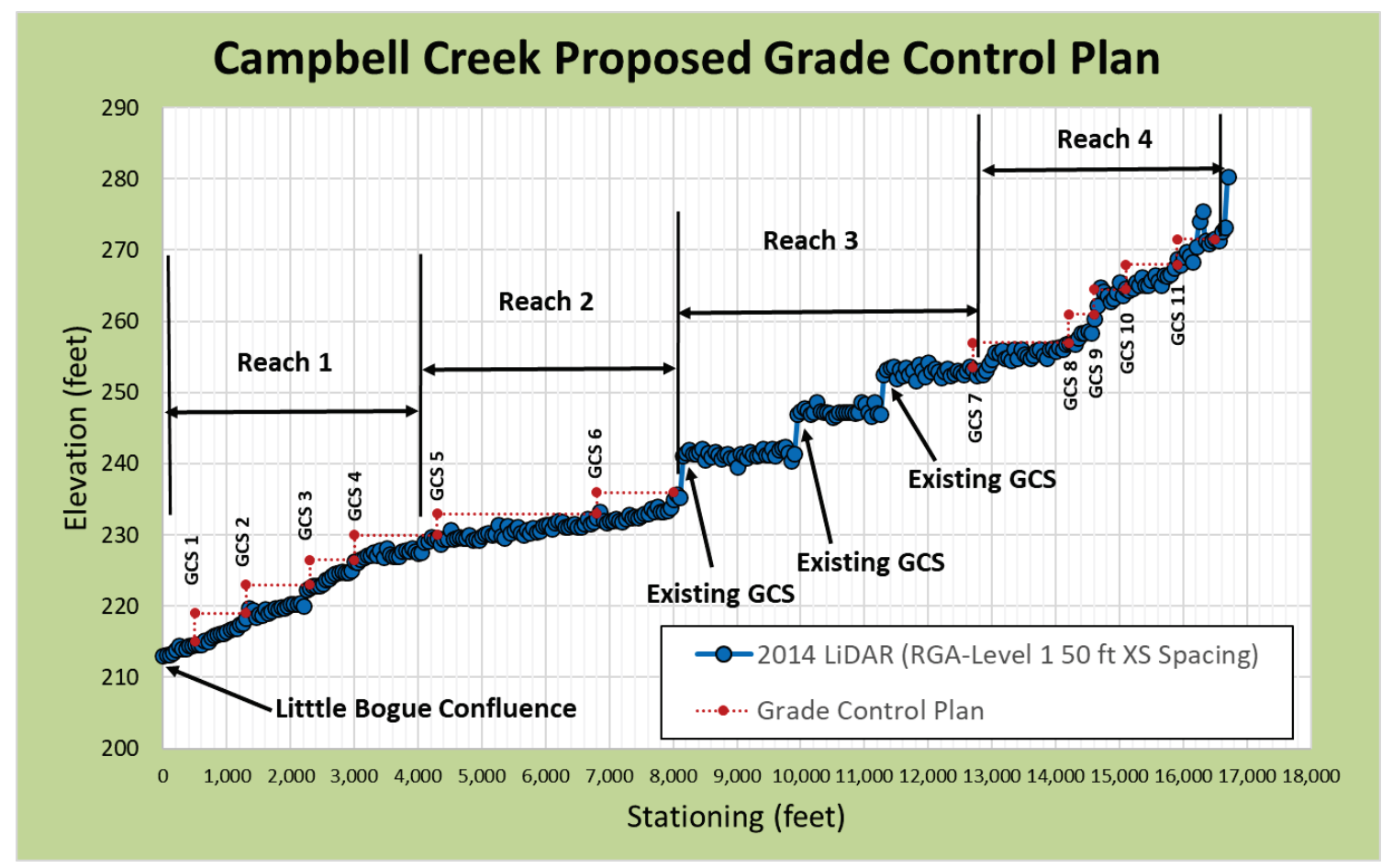

Figure 17. Grade Control Plan for Campbell Creek.

DISCUSSION: Traditionally, developing a stream stabilization plan begins with acquiring a detailed survey of the channels, involving both thalweg elevations and cross sections. This type of detailed survey can be extremely expensive, particularly when an entire watershed is being analyzed. In fact, surveying costs are often one of the largest engineering efforts, and in many studies these costs are far beyond the allowed budget. Therefore, developing more cost effective methods for obtaining channel surveys, particularly in the early planning stages, should be a high priority.

This RSM study of Campbell Creek clearly shows that LiDAR surveys provide sufficient profile and cross-sectional information to assist in a geomorphic assessment of the channel system, and the layout of a system of grade control structures. As discussed herein, the original grade control plan for Campbell Creek was developed using a detailed thalweg and cross-section survey obtained in 1986. In this case, the thalweg was surveyed approximately every $50 \mathrm{ft}$, and cross sections were taken approximately every 1,500 ft. Another detailed survey was acquired in 1991, 
which required the structure locations and crest elevations to be modified. This is often the case when planning grade control and bank stabilization structures. Therefore, using simplified, more cost-effective survey techniques such as LiDAR may be more appropriate in these situations. For this study, an existing LiDAR survey from 2014 was used, but if this were a real project, a new LiDAR survey should be obtained cost effectively with unmanned aerial vehicles/drones. Although no cost comparisons were conducted as part of this study, the collection of a LiDAR survey from a fixed wing aircraft focused only on the channel and floodplain areas has the possibility of being considerably more economical than a traditional ground survey. LiDAR resolution and cost comparisons are further discussed in Geomorphic Riverine Data Collection Methods *.

The grade control plan discussed above is just one of a number of possible grade control alternatives that could be developed. This design was developed primarily considering the channel profile data. The actual locations and elevations of the structures could be adjusted due to various other design considerations such as tributary locations, geotechnical considerations, flood control issues, environmental concerns, landowner issues, local drainage issues, and access issues. It is also important to recognize that it may be years between the initial planning and the actual construction, and that the channel morphology may have changed considerably during that time period. At that point a more detailed survey would need to be obtained in order to develop the final layout of structures. All these issues support the concept discussed herein that the use of relatively cheap and easily obtainable LiDAR surveys are more than adequate for the initial planning of grade control structures.

CONCLUSION: The application of the FG-RGA Level 1 CSA approach to the Campbell Creek Watershed clearly demonstrated its utility as a reconnaissance-level watershed assessment approach. LiDAR data was used to identify channel dimensions and profile as well as potential channel instability locations within the watershed. Grade control structures were laid out based on this preliminary assessment. It is also noted that the Level 1 approach should be initiated prior to the field site visits to identify areas of concern especially when time and funding resources limit the ability to field validate sites. The FG-Level 1 CSA approach provides an essential level of geomorphic detail for initial watershed assessment and meets the needs of the DHP and USACE SMART Planning watershed study initiatives.

ADDITIONAL INFORMATION: This Coastal and Hydraulic Engineering Technical Note (CHETN) was prepared as part of the Ecosystem Management and Restoration Research Program and the RSM Program.

The report was written by Chris Haring (Christopher.P.Haring@usace.army.mil) and David Biedenharn (David.S.Biedenharn@,usace.army.mil) of the U.S. Army Engineer Research and Development Center, Coastal and Hydraulics Laboratory. Deputy Program Manager for the RSM Program (RSM) is David May; Program Manager for the RSM Program, is Dr. Katherine E. Brutsché.

\footnotetext{
* Haring, C. H. In preparation. Geomorphic Data Collection Methods: LiDAR Surveys Versus Traditional Field Survey. ERDC/CHL Coastal and Hydraulic Engineering Technical Note. Vicksburg, MS: U.S. Army Engineer Research and Development Center
} 
This CHETN should be cited as follows:

Haring, C. H., and D. W. Biedenharn. 2021. Channel Assessment Tools for Rapid Watershed Assessment. ERDC/CHL CHETN-VII-24. Vicksburg, MS: U.S. Army Engineer Research and Development Center. http://dx.doi.org/10.21079/11681/40379

\section{REFERENCES}

Haring, C. H. 2019. An Assessment of a LiDAR-based Approach for Estimating Hydraulic Geometry Regional and Regime Relationship Curves for the Southern Driftless Area of the Midwest. Contributors: F. H. Weirich, B. D. Cramer, J. A. Dorale, T. C. Foster, and L. J. Weber. PhD dissertation. University of Iowa.

Haring, C. H., C. H. Theiling, and M. P., Dougherty. 2020. Rapid Watershed Assessment Planning Tools Based on High-Resolution Terrain Analysis. ERDC/CHL CHETN-VII-22. Vicksburg, MS: U.S. Army Engineer Research and Development Center. http://dx.doi.org/10.21079/11681/36714

Newbury, R. W., and M. N. Gaboury. 1993. Stream Analysis and Fish Habitat Design - A Field Manual. Manitoba Natural Resources; Newbury Hydraulics, Limited. ISBN 0-969-6891-0-1.

Schumm, S. A., M. D. Harvey, and C. C. Watson. 1984. Incised Channels: Morphology, Dynamics and Control. Colorado, USA: Water Resources Publications, LLC.

NOTE: The contents of this technical note are not to be used for advertising, publication,

or promotional purposes. Citation of trade names does not constitute an official endorsement or approval of the use of such products. 